\title{
Hypertension in response to IL-6 during pregnancy: role of ATI-receptor activation
}

This article was published in the following Dove Press journal:

International Journal of Interferon, Cytokine and Mediator Research

3 November 201I

Number of times this article has been viewed

\section{Babbette LaMarca' \\ Joshua Speed' \\ Lillian Fournier Ray' \\ Kathy Cockrell' \\ Gerd Wallukat ${ }^{2}$ \\ Ralf Dechend ${ }^{2}$ \\ Joey Granger ${ }^{\prime}$}

'Departments of Obstetrics and Gynecology/Physiology,

Center for Excellence in Renal and Cardiovascular Research, University of Mississippi Medical Center, Jackson, MS, USA; ${ }^{2} \mathrm{HELIOS}$ Clinic, Charite, Campus-Buch and Max-Delbrueck Center, Berlin, Germany
Correspondence: Babbette LaMarca Department of Obstetrics and Gynecology, Center for Excellence in Renal and Cardiovascular Research, University of Mississippi Medical Center, Jackson, MS 39216, USA

Tel + I 60I 8I5 I402

Emailbblamarca@umsmed.edu
Background: Increases in interleukin 6 (IL-6) and agonistic autoantibodies to the angiotensin II type 1 receptor (AT1-AA) are proposed to be important links between placental ischemia and hypertension in preeclampsia.

Methods: The purpose of this study was to determine whether IL-6 (5 ng/day), infused into normal pregnant (NP) rats, increased mean arterial pressure (MAP) and AT1-AA. MAP was analyzed in the presence and absence of an angiotensin type 1 receptor (AT1R) antagonist, losartan, L.

Results: MAP and AT1-AA increased from102 \pm 2 to $118 \pm 4 \mathrm{mmHg}$ and $0.7 \pm 0.3 \mathrm{NP}$ to $14.1 \pm 1.4$ chronotropic units with chronic IL-6 infusion. MAP responses to IL- 6 were abolished in losartan pretreated rats ( $85 \pm 4$ in $\mathrm{NP}+\mathrm{L}$ vs $85 \pm 3 \mathrm{mmHg}$ in IL-6 + L).

Conclusion: These data indicate that IL-6 stimulates AT1-AA and that activation of the AT1R mediates IL-6 induced hypertension during pregnancy.

Keywords: cytokines, pregnancy, hypertension, renin angiotensin system, inflammation

\section{Introduction}

Preeclampsia occurs in at least 5\%-8\% of all pregnancies, and is defined as new onset hypertension with proteinuria during pregnancy. ${ }^{1,2}$ Typically, preeclampsia occurs after 20 weeks gestation (in the late 2 nd or 3 rd trimesters or middle to late pregnancy). While preeclampsia and other hypertensive disorders of pregnancy are a leading cause of maternal and infant illness and death, responsible for 76,000 maternal and 500,000 infant deaths each year, the underlying physiological mechanisms involved in pathogenesis of this disease remains to be fully elucidated. ${ }^{1-5}$

Recent data from our laboratory has shown that elevations in inflammatory cytokines, such as TNF alpha, interleukin-6 and activation of immune cells such as monocytes, macrophages and both $\mathrm{T}$ and $\mathrm{B}$ lymphocytes, and autoantibody generation play an important role in the pathogenesis of hypertension in response to reductions in uterine perfusion pressure. ${ }^{4-9}$ Recent obstetrical studies indicate that preeclamptic women exhibit high levels of agonistic autoantibodies to the angiotensin II type I receptor (AT1-AA).$^{10-12}$ These AT1-AA bind to and activate the AT1R and result in many of the same signaling processes as angiotensin II. Recent studies from the Xia laboratory indicate that the severity of preeclampsia strongly correlates with levels of AT1-AA. ${ }^{13}$ Our most recent proof of concept studies have demonstrated an important role for these AT1-AA in the pathogenesis of hypertension in a rat model of preeclampsia. ${ }^{6,14-16} \mathrm{We}$ have shown that chronic infusion of rat AT1-AA activate many systems suspected of playing an important role in the pathogenesis of preeclampsia, such as endothelin-1, 
reactive oxygen species, and sFlt-1 and S-endoglin during pregnancy. ${ }^{14-16}$ Although many studies have shown the importance of AT1-AA in mediating the pathophysiology associated with preeclampsia, the antigen eliciting production of the autoantibody remains unknown.

We reported that reductions in uterine perfusion pressure (RUPP) in pregnant rats is a stimulus for the AT1-AA. ${ }^{5,6} \mathrm{We}$ have also shown increased TNF alpha and IL-6 in response to RUPP in pregnant rats. ${ }^{46}$ We have further demonstrated a role for TNF alpha in mediating hypertension during pregnancy by activating both the endothelin system and by serving as a stimulus for production of AT1-AA in pregnant rats. ${ }^{4-6}$ Similar to RUPP rats, TNF alpha-induced hypertension is blunted in the presence of AT1 receptor blockade. These studies suggest a role for activation of the AT1 receptor, possibly via the AT1-AA, in mediating hypertension during pregnancy burdened by either elevated circulating TNF alpha or reduced uterine perfusion pressure.

In defining a role for IL-6 in mediating hypertension during pregnancy, we recently demonstrated that a three-fold increase in circulating IL-6, to levels comparable to RUPP rats, in normal pregnant rats significantly raised mean arterial pressure. ${ }^{8}$ In that study, we further demonstrated a role for IL-6 to decrease renal pressure natriuresis and stimulate plasma renin activity in pregnant rats while having no effect in virgin rats. While IL-6 and AT1-AA are elevated in response to placental ischemia and in women with preeclampsia, it is unknown whether IL-6, like TNF alpha, may serve as an important stimulus for the production of AT-AA during pregnancy. Moreover, it is unknown whether the hypertension associated with chronic increases in plasma IL-6 in pregnant rats is dependent upon activation of the angiotensin type 1 receptor. Therefore, with this study, we have repeated our IL-6 induced hypertensive pregnant rat model with the purpose of investigating a role for IL-6 as a potential stimulus for AT1-AA. A second aim of the study was to determine a role for activation of AT1-receptors, possibly via the AT1-AA, in mediating IL-6-induced hypertension during pregnancy.

\section{Methods}

All studies were performed in age-matched, timed pregnant Sprague Dawley rats purchased from Harlan Sprague Dawley Inc (Indianapolis, IN). Animals were housed in a temperature-controlled room $\left(23^{\circ} \mathrm{C}\right)$ with a $12: 12$ hour light/ dark cycle. All experimental procedures executed in this study were in accordance with National Institutes of Health guidelines for use and care of animals and the Institutional
Animal Care and Use Committee (IACUC) at the University of Mississippi Medical Center approved all protocols.

\section{Experimental design Protocol I}

\section{Effect of IL-6 on ATI-AA in pregnant rats}

We have previously demonstrated a role for IL-6 to induce hypertension during pregnancy. ${ }^{8}$ This experimental protocol was performed to determine the role of AT1-AA production as a potential mechanism of IL-6 induced hypertension. Experiments were performed in normal pregnant rats divided into two groups: normal pregnant (NP) rats, $n=6$, and chronic IL-6 infused NP rats, $\mathrm{n}=6$. IL-6 (5 ng/day). Recombinant rat IL-6 (R\&D Systems, Minneapolis, MN) was infused via mini-osmotic pumps (model 2002; Alzet Scientific Corporation, Palto Alto, CA) for 5 days into normal pregnant rats during days 14 to 19 of gestation. The previously published dose (2.5 ng/day) did not cause the three-fold increase in circulating IL-6 and resulted in small increases in MAP. ${ }^{8}$ Therefore, in this study we increased the infusion dose in order to induce a comparable three-fold rise in circulating IL-6 while having a comparable effect on the blood pressure increase as previously reported. ${ }^{8}$ Carotid catheters were inserted on day 18 of gestation and MAP was determined on day 19 as described previously. ${ }^{5-8,14-16}$

\section{Determination of serum IL-6 levels}

Colorimetric ELISA (R\&D Systems, Minneapolis, MN) was used for quantification of serum IL-6 levels. This ELISA kit has been modified by the manufacturer since our previous publication. ${ }^{8}$ Inter and intra assay precision was $10.0 \%$ and $8.8 \%$, respectively. This assay displayed a sensitivity level of less than $21 \mathrm{pg} / \mathrm{mL}$.

\section{Determination of AT I-AA}

Antibodies were detected by the chronotropic responses to AT1 receptor-mediated stimulation of cultured neonatal rat cardiomyocytes coupled with receptor-specific antagonists as previously described. ${ }^{6,14-16}$ Chronotropic responses were measured and expressed in beats per minute (bpm).

\section{Protocol 2}

\section{Effect of ATI receptor antagonism on MAP in response to IL-6 in pregnant rats}

To determine the role of AT1-receptor activation in mediating IL-6 induced hypertension, two additional groups of pregnant rats were used in which IL-6 was infused into normal pregnant rats treated with losartan $(10 \mathrm{mg} /$ day $)$ in the 
drinking water. Experiments were performed in two groups of rats: NP treated orally with the AT1 receptor antagonist, losartan, NP $+\mathrm{L}, \mathrm{n}=8$, and chronic IL-6 infused NP treated orally with the AT1 receptor antagonist, losartan, NP + IL-6 + L, $\mathrm{n}=6$. On day 18 of gestation arterial catheters were inserted and MAP was analyzed as described previously. ${ }^{5-7,14-16}$

\section{Statistical analysis}

All data are expressed as mean + SEM. Student's $t$-test was used for comparison of AT1-AA among NP and IL-6 infused groups. A value of $P<0.05$ was considered statistically significant. Statistical analyses were carried out using Prism (GraphPad Software, Inc, La Jolla, CA).

\section{Results}

\section{Protocol I}

Effect of IL-6 on ATI-AA and arterial pressure in pregnant rats

As previously shown and repeated here, infusion of IL-6 into normal pregnant rats increases mean arterial pressure. ${ }^{8}$ Figure 1 demonstrates that serum IL-6 increases with chronic infusion from $63 \pm 5 \mathrm{pg} / \mathrm{mL}$ to $207 \pm 54 \mathrm{pg} / \mathrm{mL}(P<0.05)$. The increase in circulating IL-6 was associated with an increase in MAP from $102 \pm 2$ to $118 \pm 4 \mathrm{mmHg}$. In addition, the increase in circulating IL-6 was associated with production of AT1-AA in pregnant rats. AT1-AA increased markedly with chronic IL-6 (0.7 \pm 0.3 bpm NP vs $14.1 \pm 1.4$ bpm IL-6 NP,
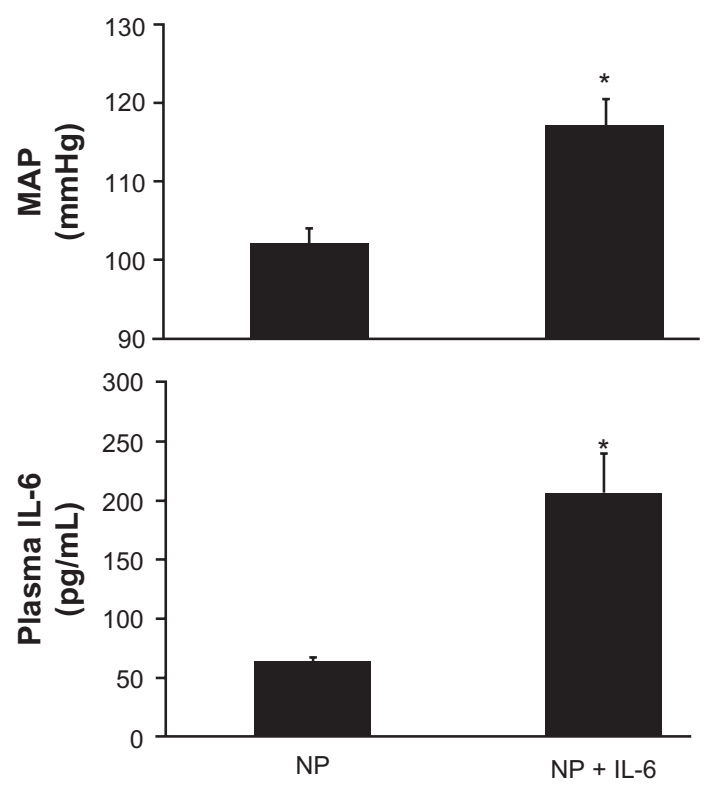

Figure I Blood pressure, MAP, increases significantly with a three-fold increase in circulating IL-6, chronically infused into pregnant rats. Note: $* P<0.05$.

Abbreviation: MAP, mean arterial pressure.
$P<0.01$; Figure 2). In our previous study, IL-6 induced hypertension was associated with elevated plasma renin activity. Therefore we measured plasma ANGII via HPLC in the current study (Wake Forest University) and found it to be elevated, albeit, not significantly, with chronic IL-6 infusion $(22 \pm 2 \mathrm{fmol} / \mathrm{mg}$ in NP vs $36 \pm 9.5 \mathrm{fmol} / \mathrm{mg}[P=0.11]$ in IL-6 infused rats).

\section{Protocol 2}

\section{Effect of ATI receptor antagonism on MAP} in response to IL-6 in pregnant rats

This set of experiments was performed to determine if activation of the AT1 receptor in response to excess IL-6 during pregnancy potentially mediates hypertension. As in the losartan untreated group, infusion of IL-6 increased circulating levels of the cytokine from $49 \pm 3 \mathrm{pg} / \mathrm{mL}$ in $\mathrm{NP}+\mathrm{L}$ rats to $212 \pm 47 \mathrm{pg} / \mathrm{mL}(P<0.05)$ in NP + IL-6 + L rats Figure 3. Although chronic infusion of IL-6 significantly elevated circulating IL-6 in losartan treated pregnant treated rats, chronic AT1 R blockade attenuated IL-6 induced hypertension. MAP was $85 \pm 4 \mathrm{mmHg}$ in NP + L rats vs $85 \pm 5$ in NP + IL- 6 + L pregnant rats (Figure 3).

\section{Effect of chronic IL-6 and ATI receptor antagonism on pup and placental weights}

There were no changes in pup weight in response to chronic IL-6 or losartan treatment. Pup weights were $2.4 \pm 0.4 \mathrm{~g}$ in NP rats and were $2.3 \pm 0.4 \mathrm{~g}$ in IL- 6 treated rats. In the losartan treated groups pup weights were $2.1 \pm 0.4 \mathrm{~g}$ in $\mathrm{NP}+\mathrm{L}$ and were $2.4 \pm 0.5 \mathrm{~g}$ in NP + IL- $6+\mathrm{L}$. The only significant differences among placental weights were seen between $\mathrm{NP}$ and NP + IL6 + L groups $(P<0.05)$. Placental weights were $0.61 \pm 0.02 \mathrm{~g}$ in NP vs $0.52 \pm 0.02 \mathrm{~g}$ in NP + IL6. In the losartan treated group placental weights were $0.55 \pm 0.01 \mathrm{~g}$ in NP + L vs $0.51 \pm 0.03 \mathrm{~g}$ in NP + IL-6 + L rats. There were

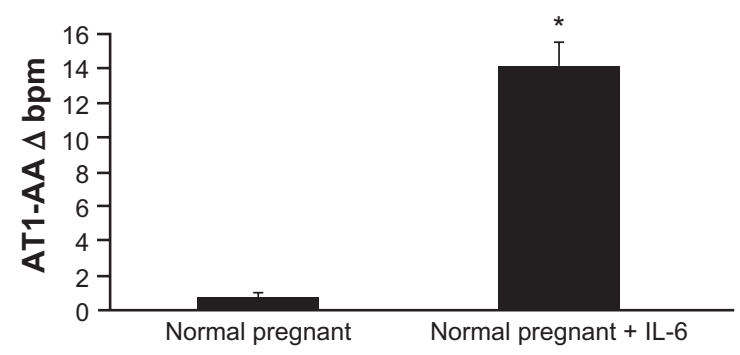

Figure 2 ATI-AA, measured by bpm, is stimulated in response to chronic IL-6 infusion onto pregnant rats.

Note: $* p<0.05$.

Abbreviations: ATI-AA, agonistic autoantibodies to the angiotensin II type I receptor; IL-6, interleukin-6. 


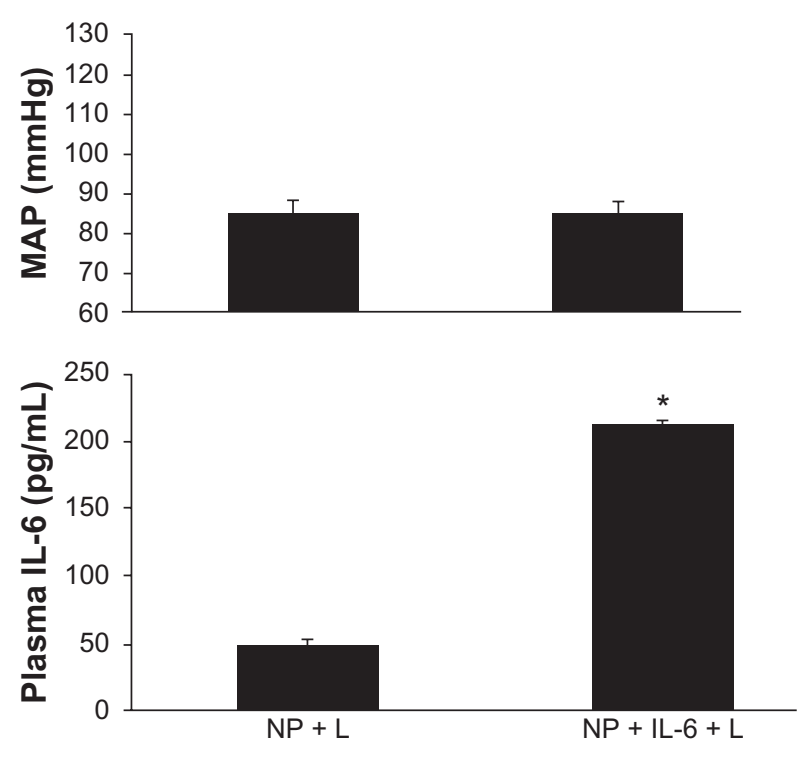

Figure 3 Blood Pressure, MAP, increases in response to a 3 -fold increase in circulating IL-6, chronically infused into pregnant rats is attenuated in pregnant rats treated chronically with losartan.

Note: $* P<0.05$.

Abbreviations: MAP, mean arterial blood pressure; IL-6, interleukin-6.

no major differences in litter size in response to IL-6 infusion or losartan treatment among the groups.

\section{Comment}

Although preeclampsia is one of the major causes of maternal and perinatal mortality and morbidity, the pathophysiology of this disease has yet to be completely understood. The initiating event of the disease is associated with abnormal cytotrophoblast invasion resulting in inadequate remodeling of the uterine spiral arteries and reduced blood flow to the utero-placental unit. ${ }^{1-5}$ The poorly perfused and hypoxic placenta is thought to release factors that result in vasoconstriction and hypertension in the mother. Wallukat and colleagues were the first to show that preeclamptic women develop stimulatory autoantibodies against the AT1 receptor. ${ }^{9-12}$ We previously reported that a reduction in placental perfusion is an important stimulus for AT1-AA production in pregnant rats. ${ }^{4-6}$

While AT1-AA are elevated in response to placental ischemia, the mechanisms linking placental ischemia and AT1-AA production have yet to be fully elucidated. ${ }^{4-16}$ It is possible that the generation of AT1-AA in response to RUPP is secondary to the increased maternal inflammatory response known to be associated with placental ischemia. We reported that serum IL-6 is elevated in RUPP rats, and infusion of IL-6 into pregnant rats increases arterial pressure and decreases renal hemodynamics. ${ }^{8}$ In the present study, we not only confirm that chronic infusion of IL-6 into pregnant rats increases arterial pressure but we also provide novel data demonstrating that the hypertension associated with IL-6 infusion in pregnant rats results in production of the AT1-AA. In addition, there is an important association between IL- 6 and activation of the endogenous angiotensin II system as shown by previous investigators. ${ }^{17-22}$ These investigators demonstrated that IL-6 is released from vascular tissue in response to ANGII and that acute, ANGII-dependent hypertension is attenuated in IL-6 knockout (KO) mice. ${ }^{21,22}$ We have reported that chronic IL-6 increased plasma renin activity and here we report that ANGII slightly increased with IL-6 infusion while AT1-AA markedly increased. However, the results of this study do not distinguish among the effects of endogenous ANGII or endogenous AT1-AA to mediate the blood pressure effects seen in response to IL-6 during pregnancy.

While blood pressure and AT1-AA levels are elevated in pregnant rats with chronic elevations in circulating IL-6, the importance of AT1-receptor activation in causing hypertension in IL-6 hypertensive rats is unclear. Therefore, a second major objective of our study was to determine the importance of AT1-receptor activation in mediating the increase in blood pressure in response to chronic IL-6 excess in pregnant rats. We report in this study that treatment with a selective AT1 receptor antagonist, losartan, abolished the hypertensive response to IL-6 during pregnancy. Although our findings indicate that AT1 receptor activation, in part, contributes to the increase in blood pressure in IL-6 hypertensive rats, our results do not quantify the relative importance of the AT1-AA and endogenously formed angiotensin II in activating the AT1 receptor. Future studies will be needed to isolate the independent contributions of endogenous ANG II vs the AT1-AA in activating the AT1 receptor when IL-6 is elevated during pregnancy. Studies that inhibited either ANGII or AT1-AA production during IL-6-induced hypertension are important to further elucidate mechanisms mediating hypertension in response to elevated IL-6 during pregnancy. However, since ANGII is not significantly elevated, and the AT1-AA is markedly increased, our interpretation is that the blood pressure response could be the result of the AT1-AA activating the AT1 R in response to elevated IL-6.

Although the exact mechanism whereby IL-6 stimulates the production of AT1-AA remains to be defined, IL-6 is known to be a major stimulus for B-cell proliferation and is a regulator of various $\mathrm{T}$ cell signaling processes. ${ }^{23,24} \mathrm{In}$ rodents and humans, polarization and differentiation of autoimmune associated CD4 + T helper 17 cells from naïve T helper cells 
is dependent upon IL-6. We now know that preeclampsia is associated with increased IL-6 and CD4 + T cells..$^{25,26}$ Furthermore our laboratory has recently shown that CD4 + T cells are increased in placental ischemic pregnant rats. ${ }^{27}$ Adoptive transfer of these CD4 + T cells induced hypertension and inflammatory cytokines such as TNF alpha, IL-6, and sFlt-1 in normal pregnant recipient rats, thereby indicating the importance of immune cells stimulated in response to placental ischemia to cause hypertension and alterations in angiogenic factors during pregnancy. ${ }^{27}$ Further studies examining a role for CD4 $+\mathrm{T}$ cells to lead to production of AT1-AA during pregnancy will be important to further our understanding in preeclamptic research.

Although our study shows increases in blood pressure in response to IL-6 infusion, this increase is not as dramatic as that seen in preeclamptic women. Furthermore we see no difference in pup weights between normal pregnant rats and those chronically treated either with IL-6 or losartan, however, intrauterine growth restriction is a common characteristic of preeclampsia. Although the IL-6 induced hypertensive pregnant rat model is a good tool to examine factors stimulated in response to the cytokine during pregnancy, it is not the only factor influencing blood pressure or fetal perfusion and growth in response to placental ischemia. Identifying factors that may play a role in this disease in humans is a driving force for this type of research, however, studying mechanisms linking hypertension with placental ischemia is obviously limited in the hospital patient setting. Therefore, it is important that studies are designed to test the importance of endogenous IL-6 producing T helper cells to stimulate B lymphocyte AT1-AA production and to activate vasoactive mechanisms and reduce renal sodium excretory function associated with hypertension in response to placental ischemia in the pregnant rat. Knowledge gained from these types of studies in animal models mimicking this disease may lead to a better understanding of the pathophysiological mechanisms associated with hypertension during preeclampsia. In summary, these data indicate that IL- 6 serves as a stimulus of immune mechanisms leading to B cell production of AT1-AA and that activation of the AT1 receptor appears to mediate hypertension associated with excessive IL-6 during preeclampsia.

\section{Acknowledgments}

This work was supported by AHA SDG0835472N; NIH grants HL78147 and HL51971. RD is supported by the German Research Foundation (DFG 631/7-1).

\section{Disclosure}

The authors report no conflicts of interest in this work.

\section{References}

1. Roberts JM, Pearson G, Cutler J, Lindheimer M. Summary of the NHLBI working group on research on hypertension during pregnancy. Hypertension. 2003;41(3):437-445.

2. Fisher SJ, Martin JM. In: Lindheimer M, Roberts JM, Cunningham FG, editors. Chesley's hypertensive disorders in pregnancy, 2nd edition. San Diego, CA: Appleton and Lange; 1998:377-394.

3. Conrad KP, Benyo DF. Placental cytokines and the pathogenesis of preeclampsia. Am J Reprod Immunol. 1997;37(3):240-249.

4. Granger JP, Alexander BT, Bennett WA, Khalil RA. Pathophysiology of pregnancy-induced hypertension. Am J Hypertens. 2001;14(6 Pt 2):S178-S185.

5. Lamarca B. The role of immune activation in contributing to vascular dysfunction and the pathophysiology of hypertension during preeclampsia. Minerva Ginecol. 2010;62(2):105-120.

6. LaMarca BB, Wallukat G, Llinas M, Herse F, Dechend R, Granger JP. Elevated agonistic autoantibodies to the angiotensin type 1 (AT1-AA) receptor in response to placental ischemia and TNF alpha in pregnant rats. Hypertension. 2008;52(6):1168-1172.

7. Sedeek MH, Llinas MT, Drummond H, et al. Role of reactive oxygen species in endothelin-induced hypertension. Hypertension. 2003;42(4): 806-810.

8. Gadonski G, LaMarca BB, Sullivan E, Bennett W, Chandler D, Granger JP. Hypertension produced by reductions in uterine perfusion in the pregnant rat: role of interleukin-6. Hypertension. 2006;48(4):711-716.

9. Dechend R, Gratze P, Wallukat G, et al. Agonistic autoantibodies to the AT1 receptor in a transgenic rat model of preeclampsia. Hypertension. 2005;45(4):742-746.

10. Wallukat G, Homuth V, Fischer T, et al. Patients with preeclampsia develop agonistic autoantibodies against the angiotensin AT1 receptor. J Clin Invest. 1999;103(7):945-952.

11. Dechend R, Homuth V, Wallukat G, et al. Agonistic antibodies directed at the angiotensin II, AT1 receptor in preeclampsia. $J$ Soc Gynecol Investig. 2006;13(2):79-86.

12. Dechend R, Mueller DN, Wallukat G, et al. Activating auto-antibodies against the AT1 receptor in preeclampsia. Autoimmun Rev. 2005;4(1): $61-65$.

13. Siddiqui AH, Irani RA, Blackwell SC, Ramin SM, Kellems RE, Xia Y. Angiotensin receptor agonistic autoantibody is highly prevalent in preeclampsia: correlation with disease severity. Hypertension. 2010; 55(2):386-393.

14. LaMarca B, Parrish M, Ray L, et al. Hypertension in response to autoantibodies to the angiotensin II type I receptor (AT1-AA) in pregnant rats: role of endothelin-1. Hypertension. 2009;54(4):905-909.

15. Parrish MR, Murphy SR, Rutland S, et al. The effect of immune factors, tumor necrosis factor-alpha, and agonistic autoantibodies to the angiotensin II Type I receptor on soluble FMS-like tyrosine-1 and soluble endoglin production in response to hypertension during pregnancy. $A m$ J Hypertens. 2010;23(8):911-916.

16. Parrish MR, Wallace K, Tam KB, et al. Hypertension in response to AT1-AA: role of reactive oxygen species in pregnancy-induced hypertension. Am J Hypertens. 2011;24(7):835-840.

17. Kranzhofer R, Schmidt J, Pfeiffer CA, Hagl S, Libby P, Kubler W. Angiotensin induces inflammatory activation of human vascular smooth muscle cells. Arterioscler Thromb Vasc Biol. 1999;19(7):1623-1629.

18. Funakoshi $\mathrm{Y}$, Ichiki T, Ito $\mathrm{K}$, Takeshita A. Induction of interleukin-6 expression by angiotensin II in rat vascular smooth muscle cells. Hypertension. 1999;34(1):118-125.

19. Han Y, Runge MS, Brasier AR. Angiotensin II induces interleukin-6 transcription in vascular smooth muscle cells through pleiotropic activation of nuclear factor-kappa B transcription factors. Circ Res. 1999; 84(6):695-703. 
20. Moriyama T, Fujibayashi M, Fujiwara Y, et al. Angiotensin II stimulates interleukin-6 release from cultured mouse mesangial cells. J Am Soc Nephrol. 1995;6(1):95-101.

21. Lee DL, Webb RC, Brands MW. Sympathetic and angiotensindependent hypertension during cage-switch stress in mice. Am J Physiol Regul Integr Comp Physiol. 2004;287(6):R1394-R1398.

22. Lee DL, Leite R, Fleming C, Pollock JS, Webb RC, Brands MW. Hypertensive response to acute stress is attenuated in interleukin-6 knockout mice. Hypertension. 2004;44(3):259-263.

23. Abbas A. Cellular and molecular immunology. Philadelphia, PA: Elsevier; 2008.
24. Cruse J, Lewis R, editors. Illustrated dictionary of immunology. 3rd edition. New York: CRC Press; 2009.

25. Santner-Nanan B, Peek M, Khanam R, et al. Systemic increase in the ratio between FoxP $3+$ and IL-17 producing CD $4+\mathrm{T}$ cells in healthy pregnancy but not in preeclampsia. J Immunol. 2009;183(11):7023-7030.

26. Sargent I, Borzychowski A, Redman C. Immunoregulation in normal pregnancy and preeclampsia: an overview. Reprod Biomed Online 2006; 13(5):680-686.

27. Wallace K, Richards S, Dhillon P, et al. CD4 + T-helper cells stimulated in response to placental ischemia mediate hypertension during pregnancy. Hypertension. 2011;57(5):949-955.

\section{Publish your work in this journal}

The International Journal of Interferon, Cytokine and Mediator Research is an international, peer-reviewed, open-access, online journal. The focus of the journal is to publish original research, reports, editorials, reviews and commentaries on all aspects of interferon, cytokine and mediators of inflammation from labora- tory science to therapeutic indications and clinical studies. The manuscript management system is completely online and includes a very quick and fair peer-review system, which is all easy to use. Visit http://www.dovepress.com/testimonials.php to read real quotes from published authors.

Submit your manuscript here: http://www.dovepress.com/international-journal-of-interferon-cytokine-and-mediator-research-journal 